\title{
Market Driving at the Bottom of the Pyramid (BoP): An Analysis of Social Enterprises
}

\section{from the Healthcare Sector}

\begin{abstract}
To date, scholarly understanding of external dimensions of market driving for the purposes of 'societal change' is largely unexplored in both developed and emerging market contexts. This paper uses a multiple case study approach to understand how market driving social enterprises (across the hybrid spectrum) create societal change in emerging markets. By drawing on Scott's (1995) three-part conceptualization of institutional legitimacy, this study explores how regulative, normative and cognitive legitimacies are invoked by market driving social enterprises at the Bottom of the Pyramid (BoP). Key contributions of the study show that all three dimensions of legitimacy are relevant but they need to be invoked in a specific order based on necessary and optional conditions. An implication of the study is that market driving through societal change can lead to the construction of new and more inclusive healthcare markets.
\end{abstract}

\section{Keywords}

Market Driving; Social Enterprises; Institutional Legitimacy; Emerging Markets; Bottom of the Pyramid 


\section{Introduction}

Emerging markets also known as Bottom of the Pyramid (hereafter BoP) and subsistence markets (Viswanathan and Rosa 2007) are typically characterized by high levels of poverty, illiteracy and unemployment rates. The presence of high bureaucracy and unstable government policies are also seen as huge challenges in such markets (Marquis and Raynard 2015).

In BoP contexts the complex interlinkages of the informal (as per customs, traditions, religious beliefs) and formal institutions (government, laws, constitution) are often identified as the sources for institutional voids (McKague et al. 2015). Although, these institutional voids lead to weak regulatory structures and the market exclusion of BoP customers (to access healthcare, education, electricity etc.), they also enable entrepreneurial opportunities (Mair et al. 2012). Research has found that social enterprises, a type of hybrid organization that combine aspects of charity and business (Battilana and Lee 2014) have played an exceptional role in utilizing the hidden business opportunities within institutional voids. They have been rather successful in compensating for a lack of institutional structure and constructing new markets that are inclusive of BoP segments (Mair et al. 2012; Wright et al. 2005).

Drawing from key marketing literature, this approach of constructing or designing new markets or institutional structures have been identified as "market driving" behavior of a firm (Jaworski et al. 2000). 'Market driving', at least in the context of advanced economies is a relatively wellresearched approach and has been positively associated with generating sustainable competitive advantage (Jaworski et al. 2000; Kumar et al. 2000; Harris and Cai 2002; Carrillat et al. 2004; Berghman et al. 2006; Ghauri et al. 2016). Extant literature has discussed "market driving" from perspectives of the 'external activities' and 'internal capabilities' of the firm (Ghauri et al. 2016; Jaworski et al. 2000; Kumar et al. 2000). Ghauri et al. (2011) identified four main external market driving activities: Changing customer perceptions, modifying competitive 
conditions, restructuring value chains and societal change. However, the majority of "marketdriving" literature is focused on advanced economies and scholars have typically focused on the first three external activities and ignored the dimension of "societal change" (which is a core focus of this research). Little is thus known about how market driving behavior can be enacted through influencing society (Tuominen et al. 2004; Berghman et al. 2006; Ghauri et al. 2011, 2016). Considering this aspect important in an emerging market context, this paper sets out to answer the following research question:

How do market driving social enterprises create societal change and what are the implications of this in emerging markets?

Taking social enterprises as case examples, this research uses institutional legitimacy as a central concept (Mair et al. 2012; Scott 1995) to explore "market driving" behavior in emerging markets. In particular, this research utilizes Scott's (1995) three-part conceptualization of institutional legitimacy to understand how the market driving behavior of social enterprises happens in an emerging market context and the implications of this for the BoP.

In line with the call to address the paucity of research on emerging markets related to business marketing (Biggemann and Fam 2011) this research enhances the literature on 'market driving' from an emerging market perspective. Contributions of this study showcase how social enterprises are enacting 'market driving' behavior by creating new healthcare markets, catalyzing new entrepreneurs, legitimizing new actors, creating new job opportunities and customers at the BoP.

As the first study to explore how institutional legitimacy is purported by market driving social enterprises in emerging markets, we find that an interplay of both normative and regulative legitimacies are required for market driving to happen. In particular, socio-cultural bridging and the formation of partnerships are necessary pre-conditions for establishing societal change. 
Study also demonstrates creation of new and more inclusive healthcare markets as an implication to market driving behavior in emerging market context.

The structure of the paper is as follows. First, background literature on market driving is presented, following a discussion on social enterprises in an emerging market context and institutional theory. Then, a conceptual framework is presented followed by details on the research setting and methodology. Next, findings of the research are presented. The paper concludes with discussion and implications along with a section on limitations and future research.

\section{Literature Review}

\section{Market Driving: Internal vs. External Dimensions}

In marketing literature, the term 'market driving' stems from the concept of market orientation (McKitterick 1957). Market orientation emphasizes the need to understand customer needs and subsequently adapt market offerings to gain competitive advantage (Kohli and Jaworski 1990, Berghman et al. 2006; Ghauri et al. 2016). Jaworski et al. (2000) proposed two approaches of market orientation, namely 'market driven' and 'market driving' approaches. In comparison to 'market driven', the 'market driving' approach was viewed more favorably as a proactive approach that could revolutionize the markets.

The market driving approach is defined as changing the composition of roles or behaviors of players in a market (Ghauri et al. 2016; Jaworski et al. 2000). Jaworski et al. (2000) categorize the implications of market driving approaches into 1) the deconstruction/ elimination of players in the market 2) the construction/ adding or building of new players to meet and deliver customer needs and 3) the modification or changing of integrating functions by key players. To date, the majority of research on market driving behavior amongst firms has been studied from 
two perspectives, related to either the 'external activities' or the 'internal capabilities' of the firm (Ghauri et al. 2016; Jaworski et al. 2000; Kumar et al. 2000) as shown in Table 1. The internal perspective of market driving forces is guided by organizational capabilities and unique business processes (e.g. business model or business structure). The external perspective is typically focused on understanding the latent needs of customers to reshape 'customer perceptions' (e.g. through partnering with the customer), changing the 'competitive landscape' (e.g. by modifying competitive conditions) and redeveloping 'supply chain networks' (e.g. by creating strong collaborative ties with partners/ suppliers) as well as generating societal impact (e.g. by engaging in politics and building local trust) (see table 1). Table 1 provides an overview of market driving literature and categorizes studies based on their focus on 'external or internal' dimensions, type of market and type of enterprises.

\section{Insert Table 1 Here}

Table 1 clearly shows that the majority of studies are focused on market driving approaches for for-profit firms within developed markets and reveals the paucity of research on the external dimension of 'societal change' in an emerging market context. Focus on societal impact to date has been narrow and limited to influencing political networks (see Elg et al. 2008). With an exception to Kumar et al. (2000), the majority of research focusing on emerging markets offers insights on adopted strategies of multinational firms venturing into new areas. For example Harris and Cai (2002) examine the market driving strategies of De Beers in the Chinese market. There is however, relatively limited applicability of research exploring local firms in an emerging market context (Kumar et al. 2000). 


\section{Social Enterprises in Emerging Markets}

The social enterprise is a typical form of a hybrid organization (figure 1). It is an organization created for a social purpose, mitigating a social problem or a market failure and to generate social value while operating with the financial discipline, innovation and determination of a private sector business (Alter 2007). These hybrids blur the boundaries between for-profit and non-profit entities by placing equal emphasis on their common-good mission and financial performance (Boyd et al. 2009). However, social enterprises as hybrids could differ widely across the hybrid spectrum, depending on their closeness to non-profits and traditional forprofits structures (Alter 2007; Bocken et al. 2016).

Non-profits are identified as organized, self-governing, voluntary organizations that are separate from government and act for public rather than for shareholders benefits (Morris 2000; Milligan et al. 2006; Salamon and Anheier 1992). They have a long history within the healthcare sector for ensuring the availability of health services at reasonable costs and quality (Marmor et al. 1986) and have been well-researched under distinct terminologies (e.g. community-based sector, voluntary sector and third sector) (Wilson et al. 2012). Apart from a social orientation, social enterprises are influenced by non-profits, especially in how they drive marketing activities that are community-driven, geographically focused and volunteer driven (Reilly 2016). Nevertheless, non-profits often suffer from constant funding issues, depending on grants and unstable incomes, however a social enterprise with a clear profit motive, has an advantage here to sustain itself and grow. Similarly, in comparison to for-profits companies, where anonymous public shares and focus on short-term shareholder value maximization distract the company from a longer-term sustainable approach (Bocken and Short, 2016), social enterprise governance models ensure clear focus on sustainability by 'corporate design'. 
Social enterprises are rising in popularity, but few models to date significantly advance the interests of the world's very poorest while also earning revenue as these beneficiaries do not fall into the viable customer segments (Battilana and Lee 2014). However, some organizations have developed models that simultaneously address both business and social goals for beneficiaries who are slightly wealthier, but still at the 'BoP' (Battilana et al. 2014; London and Hart 2004). So, while emerging countries such as India may have more loosely defined social enterprise structure, many entrepreneurs are pursuing social businesses to deliver positive impact. By reaching greater numbers of beneficiaries, social businesses can achieve greater levels of positive impact and by doing so as part of the social business (rather than a non-profit), reach economies of scale more effectively because of certainty about funding (Bocken et al. 2016).

The overarching goal of social enterprises is the same across developed and emerging countries i.e. solving societal issues through a profitable venture but the role differs significantly across these regions. In developed markets social enterprises might fill institutional voids for special groups in the society. However, in developing markets such voids are much greater and widespread. Over four billion people live in developing markets and many of those face unmet needs in areas such as education, health, energy, sanitation and financial services (Bocken et al. 2016). As developing markets emerge from low-income to middle-income status, their development offers businesses, the potential to make profits while also delivering significant social impact (Prahalad and Hart 2002; Bocken et al. 2016). In this way, organizations can fill institutional voids through creating market infrastructure. 


\section{Institutional Legitimacy}

Institutional theory has been useful to understand the behavior of firms in unstable markets (Anderson et al. 2010; Mair et al. 2012). This is highlighted by Hoskisson et al. (2000, p.252) who mention that "government and societal influences are stronger in these emerging economies than in developed economies".

Meyer and Scott (1983) have discussed legitimacy as a central notion in institutional theory defined as "the degree of cultural support for an organization" (Meyer and Scott 1983, p.201). Scholars have used this concept for understanding the process of achieving social acceptance and creating new markets (Humphreys 2010; Scaraboto and Fischer 2012). This concept is also strongly related to institutional entrepreneurship, as entrepreneurs who are dissatisfied with the market status quo induce change overcoming market stasis (Schaltegger and Wagner 2011). They may be profit-seeking firms (Phillips et al. 2004) or social enterprises seeking societal benefits (Creed et al. 2002; Maguire et al. 2004). When a new organizational form first emerges, its legitimacy is low, as its numerical rarity and novelty both mean that it must find a constituency and resources. Increasing numbers, in turn, denote rising legitimacy, as the proliferation of this form signifies success in securing support and resources (Johnson et al. 2006). The process of attaining this legitimacy comes through authorization or endorsement of particular actors in the surrounding environment (Scott 1995).

Scott (1995) explains this process using a three-part conceptualization of institutional legitimacy. First, regulative legitimacy is the means of attaining authorization or endorsement from actors who have some sort of sovereignty over organizations such as regulatory agencies, governments, who define what is legally required or acceptable via requirements and sanctions. Second, normative legitimacy as compared to legal requirements, stems from what is morally desirable and socially acceptable within the market and associates with notable examples what 
stipulate standards and values. Third, cognitive legitimacy flows from the prevalence of comparable organizational actors and rapid replication by stipulating templates for organizational structures and actions. This is strongly related to institutional entrepreneurship, as rapid replication could be achieved by inspiring and catalyzing other organizations with the provision of templates and guidelines.

\section{Conceptual Framework}

A conceptual framework representing the core theoretical areas of this paper is illustrated in figure 2. The starting point of the conceptual framework is based on delineating the type of market driving social enterprise, (i.e. non-profits, hybrids or for-profits) operating in emerging markets. The conceptual framework addresses a current gap in the market driving literature (see table 1) that shows less attention on how social enterprises are enacting marketing driving behavior in emerging markets (see Jaworski et al. 2000; Harris and Cai 2002; Ghauri et al. 2011; Tarnovskaya et al. 2008). In particular, the conceptual framework focuses on one of the external dimensions of market driving, 'societal change'. While extant literature predominantly discusses the three external dimensions of market driving (changing customer perceptions, modifying competition and restructuring value chains) this conceptual framework draws attention to the lesser explored dimension of 'societal change'(Ghauri et al. 2011).

Following this, an institutional theory lens is then adopted to frame an understanding of how market driving social enterprises are enacting 'societal change' in emerging markets. This uses a three-part conceptualization of institutional legitimacy (i.e. regulative, normative and cognitive legitimacy) (Scott 1991; Anderson et al. 2010; Mair et al. 2012). The final component of the framework, focuses on the implications of market driving behavior (adapted from Jaworski et al. 2000). This considers how the construction, deconstruction or modification of markets can occur as an outcome of market driving. 


\section{Research Setting and Methodology}

This research is set in the context of the Indian healthcare market. India is an emerging country that is facing difficult challenges in providing basic healthcare services to impoverished communities (especially in rural areas) at the BoP. The Indian market lacks a well-established social security system to ensure basic services to all its citizens (Srivastava and Shainesh 2015). These types of system are usually provided by the state or government and is often taken for granted in most advanced economies. Presence of such institutional voids in India have excluded the majority of BoP communities from accessing healthcare, as the consumption of these services is a direct hit on their disposable income (Viswanathan and Rosa 2010). In such scenarios, social enterprises are seen to be playing a crucial role in bringing affordable healthcare services to the BoP segments (Zukin and Dimaggio 1990).

\section{Sample Selection and Data Collection}

Using a case study approach (Yin 2009), this study analyzes four social enterprises operating in the Indian healthcare sector. We adopted an abductive approach (Dubois and Gadde 2002) to move between data and literature (Ghauri et al. 2016; Jaworski et al. 2000; Scott 1995). Purposive sampling was used to identify four market driving social enterprises, Aravind Eye Care (Case 1), Ziqitsa Healthcare (Case 2), LifeSpring Hospitals (Case 3) and GV Meditech (Case 4) that have shown financial sustainability and made conscious efforts to engage in social impact in the Indian healthcare market (Ghauri et al. 2016). Data was collected in the period from 2014 to 2016 . In total 12 semi-structured interviews with founders and key informants were collected and each interview lasted for approximately 45-60 minutes. Additionally, 
secondary data in the form of company documents and press releases were referenced. Details about each of the selected cases with a justification for inclusion is detailed as an Appendix.

\section{Findings}

It was identified through the case analysis that the term social enterprise is loosely defined in the Indian healthcare context. Although the four cases vary widely on the hybrid spectrum (Alter 2007) with a distinct mix of mission and market orientation (see figure 1) they all identify themselves as social enterprises. For the purpose of this study, social enterprises are categorized based on their closeness to two extremes of the hybrid spectrum - non-profit and for-profit (see table 2). Case 3 and Case 4 are private limited companies, who have high market orientation and are referred to as 'for-profit' social enterprises, while Case 1 being highly mission driven is referred to as a 'non-profit' social enterprise. Case 2 is a mix of market (a private limited company) and mission (a non-profit training institute) orientations and is termed a 'hybrid' social enterprise.

Insert Table 2 Here

Table 2 summarizes the market driving behavior undertaken by these different types of social enterprises. We now discuss each case exclusively and then do a cross-case analysis to understand how these market driving firms invoked institutional legitimacy to drive societal change.

Normative Legitimacy - Case 1 operating only in Tamil Nadu (a state in Southern India) has a strong regional focus. By operating in this region alone, they are able to communicate their healthcare services through a common language, drawing on specific population densities and cultural backgrounds. In collaboration with local community workers (i.e. community leaders, 
school teachers) several outreach camps are conducted to enable socio-cultural bridging with the local population by offering quality assurance and spreading awareness. Case 1 runs an academic and training institute called LAICO (Lions Aravind Institute of Community Ophthalmology) to develop a workforce of doctors and paramedics locally. The paramedics play an important role in offloading tasks from doctors and establishing a sense of community to boost normative legitimacy.

"Each year we take about 400-500 high school girls from villages and put them for two years of paramedic training. In this training they are trained to do some specific tasks, which literally takes off 60-70\% of the doctor's workload." - Executive Director, Aravind Eye Care.

In Case 2, however normative legitimacy was used to build more awareness about medical emergency services. In the local BoP population where the use of an ambulance to provide transportation services for emergency healthcare is not yet acknowledged, Case 2 conducts several training camps and health education programs. These educational camps are provided at multiple locations (within cities, schools and colleges) with a goal to change consumer behavior of the BoP to not take a cab but instead an ambulance to a hospital in case of medical emergencies. A non-profit sister firm of Case 2 called LIHS (LifeSupporters Institute of Health Sciences) plays an important role in further spreading awareness of emergency services by training paramedics.

"We do lot of free training camps and programs to create awareness about this and also to educate the customer in order to make them understand why an ambulance is required in an emergency. We have been acknowledged twice in the last two consecutive years for conducting the highest number of health camps"- Business Manager, Ziqitsa Healthcare.

The next case (Case 3) focuses on quality maternity care for women from poor working communities in urban and peri-urban areas in Hyderabad (a state capital in Southern India). Through conducting camps (run by local paramedics) in the community and encouraging early 
registration of pregnant women, Case 3 promotes standardized protocol-based maternity care as a new mindset in India. Apart from expecting mothers, camps target other family members who play a vital role in decision-making for healthcare. An important aspect of this standardized service is price transparency. Prices offered to the BoP are held at a constant rate for two years (referred to as a 'safety net') further enabling socio-cultural bridging and trust within local communities.

"This safety net of price is of particular relevance in the culture in which LifeSpring operates - expenses related to the first pregnancy and delivery of the first child are typically borne by the parents of the girl, who are already under a huge financial burden due to previous expenses they are paying off for the marriage of the same girl"- HR Manager, LifeSpring Hospitals.

Finally, Case 4 established in the Northern Indian city of Banaras gains normative legitimacy through active participation in local social welfare programs. Case 4 trains and imparts basic paramedic skills at the BoP. These programs spread awareness at the grassroots and also improve employability of the local BoP population. Relationship building with the BoP is primarily done through paramedics and local community workers. In a span of 3 years, Case 4 have trained more than 2450 students and encouraged them to engage in training for counselling and personalized care.

"Paramedics are of great help because they come from nearby villages, they know the language and the people so it is very easy for them to communicate and convince others about the benefits of these services. We are also using lot of school teachers in nearby areas to train the paramedics in English and basic computer skills. Teachers are also of great help as they do counseling and engage in awareness programs”- Founder, GV Meditech.

Cross-case analysis (shown in Table 3) reveals that the formation of informal networks through collaboration with local community workers have been instrumental in changing the perception of consumers at the BoP and spreading awareness of healthcare services. One to one interaction 
and personalized services (see Case 4) also facilitates relationship building at the BoP across individual and community levels. By adopting a regional focus (i.e. a defined location for healthcare service offerings targeting BoP consumers) Cases 1, 3 and 4, ensured a deeper connection with the local population and a heightened sensitivity to their needs regardless of their cultural background. Standardization of healthcare services adopted by Case 1 and 3 ensured transparency of protocols, quality and price. Table 3 below summarizes the necessary (demonstrated across all the four cases) and optional conditions for attaining normative legitimacy and invoking societal change in healthcare markets.

Insert Table 3 Here

Regulative Legitimacy - Case 1 collaborates extensively with both the state and central government in a mutually beneficial partnership to offer eye care camps and scale a basic healthcare service partially subsidized by the government. Relatively recently, the government has started providing insurance services to BoP segments. This is helpful for Case 1, as it helps them to enlarge the paid customer base for their services and partner with third party insurance companies to secure as a platform from where BoP customers can avail insured healthcare services.

"Many of the state governments including the central government offers insurance schemes where the government pays the premium for people below certain income levels to avail basic healthcare service. What we do is proactively partner with third parties, for example growing insurance companies" - Executive Director, Aravind Eye Care.

In Case 2, regulative legitimacy is demonstrated by a public-private partnership (PPP) model. In this model, Case 2 gets paid by the government to run free services for the local citizens. 
They work closely with the state governments of Rajasthan, Bihar, Punjab, Orissa, and Kerala to offer a range of services. An outcome of the PPP is the 108 model, where a helpline service is run by Case 2 to reduce IMR (Infant Mortality Rate) and MMR (Mother Mortality Rate) in the states of Rajasthan, Kerala Punjab and Bihar. In Orrisa, they launched the 102 helpline service for women and children and in Punjab they ran 104, a basic health enquiry service. Furthermore, they work with the national highway authority and insurance companies to offer emergency medical services, known as 1033 MMU (Mobile Medical Unit).

"We are not competing with the government but working with them. We work with various state governments in various capacities to help them set up toll free numbers, helplines etc." Business Manager, Ziqitsa Healthcare.

Further examples of partnership agreements are found in Case 3. By working closely with diagnostics centers, pharmacies, blood banks, medical stationaries and other big hospitals to offer a well-connected network of services to the BoP. These partnerships are important as they enable Case 3 to avoid fixed costs and sustain regulative legitimacy.

"We reduce working capital by not owning the pharmacy and diagnostics. We have tried to make most of our costs variable instead of fixed" - HR Manager, LifeSpring Hospitals

In Case 4 (similar to Case 1 and 2) they actively engage in a government scheme called SGSY (Swarnajayanti Gram Swarojgar Yojana) which provides training to the local population and equips them with basic paramedic skills. In doing so, Case 4 closely collaborates with local NGOs (e.g. ASHA) and run similar partnerships with public and private firms, insurance companies and banks to facilitate better connected medical services.

"Under the RSBY (Rashtriya Swasth Beema Yojna) scheme BoP consumers are provided with a card to undergo surgery and get paid by the government through third party insurance 
companies. We have also tied-up with nearby industries, offering a cashless service where employees don't have to pay but the company pays for them"- Founder, GV Meditech.

Cross-case analysis shown in table 4 reveals that these social enterprises engage with multiple stakeholders (both government and non-governmental) to form different modes of partnerships. Case 2, exemplifies the PPP model, Cases 3 and 4 collaborate with an array of stakeholders such as pharmacies, diagnostic centers, public and private companies. This helps them to create the regulative legitimacy needed to enact their social purpose and reduce fixed costs. Across the cases, it emerges that the development of partnerships across stakeholders is necessary to secure regulative legitimacy in emerging markets (See table 4).

Insert Table 4 Here

Cognitive Legitimacy-Case 1 operates through a network of five regional hospitals. Following a hub and spoke model, the city of Madurai (the hub) handles 18 mission centers/ primary centers (spokes), located in nearby villages. LAICO supports over 350 institutions working towards blindness prevention in the form of sharing best practices through training, workshops and visits and this enables cognitive legitimacy. In addition, rapid replication of best practices by outside institutions are establishing Case 1 as a focal brand in the market.

“LAICO are indirectly helping to build our brand reputation”- Executive Director, Aravind Eye Care.

Further replication is seen in Case 2, where the PPP model 108 service is being adopted by several state governments. For example, approval by the Rajasthan government to operate more than 300 state ambulances for emergency medical services has generated interest among other 
state governments to replicate this service. To date the 108 emergency service has been replicated in the states of Bihar, Kerala, Orrisa and Punjab.

"..we have around 1200 ambulances. We serve 3.4 million people across 17 states and have 8000 people on board. This is the kind of impact that we have been able to create within the last 5 years"- Business Manager, Ziqitsa Heathcare.

In Case 3 however, cognitive legitimacy is shown through organic expansion. They adopted a cluster approach to grow hospitals in the city of Hyderabad and in surrounding peri-urban areas. In doing so, they have developed a strong community presence among 12 hospitals that they own. This has led them to not only build market share in the local community, but put competitive pressures on neighboring hospitals who are now reducing the prices of their healthcare services to remain competitive.

"A cluster approach has helped us to reduce costs further and take advantage of the goodwill generated in the community from the first hospital in Hyderabad to the 11 others that are fully owned "- HR Manager, LifeSpring Hospitals.

In contrast to Case 3, Case 4 engages in organic expansion by following a hub and spoke model that enables 'regional growth'. They offer services at three levels across a main hub (which is a super specialty hospital), two micro clinic plus hospitals in Gazipur and Mirzapur (with 20 beds and admission facilities) and six micro clinics (that run healthcare examination facilities). Case 4 sought to expand bottom-up through fully-owned micro-clinics to ensure quality of healthcare provision and ethical services at the BoP.

"There is no quality control in India and anyone can open a hospital. We are trying to create an ecosystem where people feel confident about the healthcare services they receive."Founder, GV Meditech 
The cross-case analysis shown in table 5 reveals different conditions to develop cognitive legitimacy. Case 1 exemplifies how the sharing of best practices among comparable market players can enable cognitive legitimacy through recognition and rapid replication. The two excerpts below (from Shankara Nethralaya and Silguri Hospitals) show that through replication, Case 1 has become an endorsement brand for new institutions to follow.

"The whole thought process while setting up this hospital in 1994 was inspired by what Aravind has been doing. In fact a lot of best practices have been borrowed from Aravind by us when we were running these efforts"- Trustee and founder, Shankara Nethralaya.

"In the strategic planning workshop conducted by Aravind we saw their business model and came back with lots of insights to develop our hospital. Support of Aravind helped us to pick up business after a period of slow growth" - CEO, Siliguri Hospital.

In Case 2 however, cognitive legitimacy was gained through a PPP model which caught the attention of other state governments for potential replication and growth. Unlike the above relatively open approach of replication, Case 3 and Case 4 (both for-profit enterprises) adopted a more closed approach to expand organically. Table 5 indicates that compared to profit oriented enterprises, non-profit and hybrid enterprises attain cognitive legitimacy by showing a stronger tendency to share best practices. There are no necessary conditions found to be associated with cognitive legitimacy. Instead, different models can be used as optional conditions for market driving.

\section{Discussion and Implications}


This paper sought to understand how market driving social enterprises in emerging markets develop, constitute and enact conditions of institutional legitimacy for purposes of societal change. In doing so, this work addresses the current lack of research related to business-tobusiness firms in emerging markets (Biggemann and Fam 2011) and showcases (see figure 3) how social enterprises are able to change the rules of the game within emerging markets and enable more opportunities for inclusive growth.

This study reveals that different types of social enterprises engage in market driving behavior for societal change. The analysis shows that there is an order in which institutional legitimacy is built for market driving based on specific necessary or optional conditions. It was found that social enterprises build both normative and regulative legitimacies prior to cognitive legitimacy (see figure 3). Initially normative legitimacy is established through imparting skills and education to local BoP populations. Necessary conditions for normative legitimacy include developing relationships at the $\mathrm{BoP}$ and recruiting local BoP workforce. Whereas optional conditions are to develop a regional focus for healthcare provision or the standardization of services in terms of protocols, quality and price assurances. Alongside normative legitimacy, social enterprises need to build regulative legitimacy through collaboration with multiple stakeholders. This is also a necessary condition through which social enterprises can embed themselves into formal institutional structures with governmental and non-government stakeholders.

Once normative and regulative legitimacy are built, social enterprises are then able to draw upon cognitive legitimacy to catalyze other organizations to replicate best practices and grow organically. There are optional conditions that can be used to invoke cognitive legitimacy. These include specific models i.e. hub and spoke, PPP, cluster approach or an open model of sharing best practices. 
The analysis further reveals that implications of market driving through societal change are enabling the creation of new healthcare markets (see figure 3). This has occurred in the following three ways:

Enhancing employability of the workforce: In an emerging market environment like India, there is an evident shortage of resources, especially among healthcare professionals in rural regions. According to population distribution, $70 \%$ of Indian doctors reside in urban areas and the remaining 30\% in rural India (Srivastava and Shainesh 2015). This imbalance has left rural India suffering from inaccessible and poor quality healthcare services. Across the social enterprises studied an emphasis on developing local workforces are evident. Through established educational institutes or in collaboration with the government, social enterprises are enhancing employability of the local population by training them with basic paramedic skills. These enterprises have diffused and normalized the role of 'paramedics' in the healthcare supply chain and overcome a resource crunch. This has led to the creation of employable workforces to support newly developed healthcare ecosystems at various levels.

Inclusion of new customer segments: Spreading awareness about healthcare among BoP communities has fostered the adoption of more inclusive customer segments. Low cost and subsidized healthcare services have therefore added to traditional segmentation approaches based on payment capacity (Kumar and Puranam 2012). Socio-cultural bridging, provision of alternative channels (i.e. outreach centers) and better connected networks of stakeholders have enabled a trust and 'willingness to pay' attitude among those at the BoP. This has subsequently 
increased the overall market size of the healthcare sector by converting a larger non-consumer base into new viable consumers of healthcare services.

Redesigning quality standards: Through standardization of healthcare service, social enterprises are introducing more transparency and clear quality standards into healthcare services delivered to the BoP. In an emerging market such as India, malpractices and unnecessary medication are quite commonly prescribed by doctors for profit making. The introduction of transparent and better-integrated systems have put pressure on existing players in the market to follow suite. Quality assurance activities through personalized care are reinstating new benchmarks of standardized service are helping to construct more fair and ethical healthcare markets.

The theoretical contributions of this paper are twofold. Firstly, a theoretical contribution is made to extend understanding of market driving by using the lens of Scott's (1995) three-part conceptualization of institutional legitimacy to unpack how external dimensions of societal change can be enacted by social enterprises in emerging market contexts. In doing so, it was identified that an interplay of both normative and regulative legitimacies are required to ensure that specific conditions are met by social enterprises before market driving can happen. For societal change to occur all three dimensions of legitimacy are relevant but they need to be invoked in a specific order. In particular, socio-cultural bridging (normative legitimacy) (Marquis and Raynard 2015) and the formation of partnerships (regulative legitimacy) are necessary pre-conditions for establishing societal change. This is due to the fact that emerging markets have communistic societies and interpersonal interaction has a significant influence in shaping the formation of business relationships (Weidner et al. 2010). Subsequently, cognitive legitimacy is enabled by social enterprises through optional conditions (i.e. models) for growth and expansion. 
Secondly, this study contributes insight into how external dimensions of market driving in emerging contexts can lead to the construction of new markets that are oriented towards social impact. Currently, market driving literature lacks theoretical understanding of how market driving is fostered to influence societal change. Scholars have focused much more attention on the external dimensions of customer value, supply chains and competitive behavior (Ghauri et al. 2011, Carrillat et al. 2004, Jaworski et al. 2000, Harris and Cai 2002). By drawing on societal change as a focal external dimension, we show that market driving can lead to the formation of newer and more inclusive markets. This is seen through job creation in the healthcare sector for paramedics and doctors.

In addition, market driving is found to be pertinent to growing the size of the healthcare market in an emerging context. The 'willingness to pay' attitude from BoP communities reveal how market driving social enterprises can develop more inclusive segmentation and targeting strategies to grow the market and invoke social change. Consequently, we see how markets shaped by social enterprises (working as focal actors) are built upon partnerships that form new value systems for social change (Scott 1995). Further to this, we found that market driving can construct new markets in difficult to reach regions (i.e. rural India) but this does require a concerted effort at establishing quality standards, ethical practices and more transparency in healthcare delivery. By adhering to the call for more scholarly attention on the role of institutions in emerging economies (Rivera-Santos et al. 2012; Teegen et al. 2004) and furthering knowledge on the links between institutional environments and inter-organizational relationships (e.g. Williamson 1985), we contribute further understanding into how market driving social enterprises are pooling together to reshape emerging markets that lack sufficient regulatory structures.

The managerial implications of this study showcase the importance of organizing and structuring activities for socio-cultural bridging and localization (Ghauri et al. 2011). 
Collaboration with stakeholders should be prioritized by social enterprises through building regional networks for disseminating inter-firm knowledge. The organizing and sharing of knowledge among like-minded social enterprises across the hybrid spectrum would be a useful network to develop. It would allow for opportunities to connect with and get support from government stakeholders, local communities and those at the BoP. Furthermore, we suggest that policy makers need to explore in more depth how exchange mechanisms across multiple stakeholders can be best managed to improve social impact and create better standards to drive ethical practices in healthcare markets.

Another important implication is the insight that shaping a market is not a passive development that has to be driven by a single company alone. On the contrary, entrepreneurs try to shape markets through social enterprises regardless of mission or market orientation (Kumar et al. 2000). Learnings from this study could serve as a starting point for other social enterprises and traditional 'for-profit' firms in healthcare and other sectors (i.e. education) to attain competitive advantage in emerging markets by influencing society and driving social change.

\section{Limitations and Further Research}

We acknowledge several limitations to this study. From a methodological standpoint, the research design is based on a limited number of cases, situated in a single sector and from one emerging market alone. In addition, the selected cases vary widely in their timespan of market driving activities, which makes it difficult to gather comparative-chronological insights. It would be interesting for further research to use a mixed method approach that incorporates both qualitative and quantitative methods to understand market driving and measure the causal effects of institutional legitimacy for societal change. It would be useful for further research to also explore market driving by social enterprises across multiple emerging market settings. In doing so, different insights can be gathered on the necessary and optional conditions of institutional legitimacy needed for societal change in healthcare or related markets. 
Furthermore, we urge scholars to extend research into concerned markets, i.e. those that are riddled by political conflict, war, poverty to better understand how social enterprises are enacting market creation and designing better markets in the face of adversity (Chakrabarti and Mason 2015; Mason et al. 2012). Finally, future research in emerging market contexts should develop clearer distinctions of how social enterprises are operating across the hybrid spectrum (Alter 2007; Bocken et al. 2016). In contrast to existing literature, that has predominantly focused on traditional for-profit firms and their market driving activities, we found that in an emerging market context, both for-profit and non-profit enterprises are market driving. Further research is needed to enhance understanding on the types of market driving social enterprises operating in emerging markets. It would be helpful to see if social enterprises change their position across the hybrid spectrum from for-profit to non-profit, or vice versa when pursuing market driving and if they are able to not only construct new markets but also deconstruct or modify existing markets.

\section{References}

Alter, K. 2007. “Social Enterprise Typology,” Virtue Ventures LLC, pp. 1-31 (doi: 10.1007/s11115-013-0234-y).

Anderson, J. L., Markides, C., and Kupp, M. 2010. "The last frontier: Market creation in conflict zones, deep rural areas, and urban slums," California Management Review (52:4), University of California Press Journals, pp. 6-28 (doi: 10.1525/cmr.2010.52.4.6).

Battilana, J., and Lee, M. 2014. "Advancing Research on Hybrid Organizing - Insights from the Study of Social Enterprises," The Academy of Management Annals (8:1), pp. 397441 (doi: 10.1080/19416520.2014.893615).

Battilana, J., Sengul, M., Pache, A. C., and Model, J. 2014. "Harnessing Productive Tensions in Hybrid Organizations: The Case of Work Integration Social Enterprises," Academy of Management Journal (58:6), pp. 1658-1685 (doi: 10.5465/amj.2013.0903).

Berghman, L., Matthyssens, P., and Vandenbempt, K. 2006. "Building competences for new customer value creation: An exploratory study," Industrial Marketing Management (35:8), pp. 961-973 (doi: 10.1016/j.indmarman.2006.04.006).

Biggemann, S., and Fam, K.-S. 2011. "Business marketing in BRIC countries," Industrial Marketing Management (40:1), Elsevier, pp. 5-7 (doi:

10.1016/j.indmarman.2010.09.004). 
Bocken, N. M. P., Fil, A., and Prabhu, J. 2016. "Scaling up social businesses in developing markets," Journal of Cleaner Production (139:12), pp. 295-308 (doi: 10.1016/j.jclepro.2016.08.045.).

Boyd, B., Henning, N., Reyna, E., Welch, M., and Wang, D. 2009. Hybrid Organizations: New Business Models for Environmental Leadership, Greenleaf Publishing Limited.

Carrillat, F. A., Cano, C. R., and Jaramillo, F. 2004. "A meta-analysis of the relationship between market orientation and business performance: evidence from five continents," International Journal of research in Marketing (21:2), North-Holland, pp. 179-200 (doi: 10.1016/j.ijresmar.2003.07.001).

Creed, W. E. D., Scully, M. A., and Austin, J. R. J. R. 2002. "Clothes Make the Person? The Tailoring of Legitimating Accounts and the Social Construction of Identity," Organization Science (13:5), pp. 475-496 (doi: 10.1287/orsc.13.5.475.7814).

Dubois, A and Gadde, L.E., 2002. "Systematic Combining: An Abductive Approach to Case Research" Journal of business research, 55, pp. 553-560.

Ghauri, P. N., Elg, U., Tarnovskaya, V., and Wang, F. 2011. "Developing a market-driving strategy for foreign markets: Internal capabilities and external activities," Schmalenbachs Business Review (3:11), pp. 1-23.

Ghauri, P., Wang, F., Elg, U., and Rosendo-Ríos, V. 2016. "Market driving strategies: Beyond localization," Journal of Business Research, p. 5682 (doi: 10.1016/j.jbusres.2016.04.107).

Harris, L. C., and Cai, K. Y. 2002. "Exploring Market Driving: A Case Study of De Beers in China," Journal of Market-Focused Management (5:3), pp. 171-196 (doi: 10.1023/A:1022938605867).

Hoskisson, R. E., Eden, L., Lau, C. M., and Wright, M. 2000. "Strategy in Emerging Economies," Academy of Management Journal (43:3), pp. 249-267 (doi: $10.2307 / 1556394)$.

Humphreys, A. 2010. "Megamarketing: The Creation of Markets as a Social Process," Journal of Marketing (74:3), pp. 1-19 (doi: 10.1509/jmkg.74.2.1).

Jaworski, B., Kohli, A., and Shay, A. 2000. "Market-Driven Versus Driving Markets," Journal of the Academy of Marketing Science (28:1), pp. 45-54 (doi: 10.1177/0092070300281005).

Johnson, C., Dowd, T. J., and Ridgeway, C. L. 2006. "Legitimacy as a Social Process," Annual Review of Sociology (32:1), pp. 53-78 (doi: 10.1146/annurev.soc.32.061604.123101).

Kohli, A. K., and Jaworski, B. J. 1990. "Market Orientation: The,” (54:April), pp. 1-18.

Kumar, N., Scheer, L., and Kotler, P. 2000. "From market driven to market driving," European Management Journal (18:2), pp. 129-142 (doi: 10.1016/S02632373(99)00084-5).

London, T., and Hart, S. L. 2004. "Reinventing strategies for emerging markets: beyond the transnational model," Journal of International Business Studies, pp. 350-370 (doi: 10.1057/palgrave.jibs.8400099).

Maguire, S., Hardy, C., and Lawrence, T. B. 2004. "Institutional Entrepreneurship in 
Emerging Fields: HIV/AIDS Treatment Advocacy in Canada," The Academy of Management Journal (47:5), Academy of Management, pp. 657-679 (doi:

10.2307/20159610).

Mair, J., Marti, I., and Ventresca, M. 2012. "Building inclusive markets in rural Bangladesh : How intermediaries work institutional voids," Academy of Management Journal (55:4), pp. 819-850 (doi: 10.5465/amj.2010.0627).

Marquis, C., and Raynard, M. 2015. "Institutional Strategies in Emerging Markets," The Academy of Management Annals (9:1), pp. 291-335 (doi: 10.1080/19416520.2015.1014661).

McKague, K., Zietsma, C., and Oliver, C. 2015. "Building the Social Structure of a Market," Organization Studies (36:5), pp. 1063-1093 (doi: 10.1177/0170840615613370).

McKitterick, T. E. M. 1957. "The Problem of Egypt," The Political Quarterly (28:2), Blackwell Publishing Ltd, pp. 118-122 (doi: 10.1111/j.1467-923X.1957.tb01858.x).

Meyer, J. W., and Scott, W. R. 1983. "Organizational environments: Ritual and rationality," Journal of Policy Analysis and Management (3:4), Wiley Subscription Services, Inc., A Wiley Company, p. 626 (doi: 10.1002/pam.4050030417).

Phillips, N., Lawrence, T. B., and Hardy, C. 2004. "Discourse and Institutions," The Academy of Management Review (29:4), p. 635 (doi: 10.2307/20159075).

Prahalad, C. K., and Hart, S. L. 2002. "The Fortune at the Bottom of the Pyramid," Strategy+Business Magazine (26), p. 273 (doi: 10.2139/ssrn.914518).

Rivera-Santos, M., Rufín, C., and Kolk, A. 2012. "Bridging the institutional divide: Partnerships in subsistence markets," Journal of Business Research (65:12), pp. 17211727 (doi: 10.1016/j.jbusres.2012.02.013).

Scaraboto, D., and Fischer, E. 2012. "Frustrated Fatshionistas: An Institutional Theory Perspective on Consumer Quests for Greater Choice in Mainstream Markets," Journal of Consumer Research (39:6), pp. 1234-1257 (doi: 10.1086/668298).

Schaltegger, S., and Wagner, M. 2011. "Sustainable entrepreneurship and sustainability innovation: categories and interactions," Business Strategy and the Environment (20:4), John Wiley \& Sons, Ltd., pp. 222-237 (doi: 10.1002/bse.682).

Scott, W. R. 1991. "Unpacking institutional arguments," in The new institutionalism in organizational analysisW. W. Powell and P. J. DiMaggio (eds.), Chicago: University of Chicago Press, pp. 164-182.

Scott, W. R. 1995. Institutions and OrganizationsFoundations for organizational science, Thousand Oaks: SAGE Publications (doi: 10.3917/mana.172.0136).

Srivastava, S. C., and Shainesh, G. 2015. "Bridging the service divide through digitally enabled service innovations: Evidence from indian healthcare service providers," $M I S$ Quarterly (39:1), pp. 245-267.

Teegen, H., Doh, J. P., and Vachani, S. 2004. “The importance of nongovernmental organizations (NGOs) in global governance and value creation: an international business research agenda," Journal of International Business Studies (35:6), pp. 463-483 (doi: 10.1057/palgrave.jibs.8400112).

Tuominen, M., Rajala, A., and Möller, K. 2004. "Market-driving versus market-driven: 
Divergent roles of market orientation in business relationships," Industrial Marketing Management (33:3), pp. 207-217 (doi: 10.1016/j.indmarman.2003.10.010).

Viswanathan, M., and Rosa, J. A. 2007. "Product and Market Development for Subsistence Marketplaces: Consumption and Entrepreneurship beyond Literacy and Resource Barriers," in Product and Market Development for Subsistence MarketplacesAdvances in International Management (Vol. 20), Emerald Group Publishing Limited, pp. 1-17 (doi: doi:10.1016/S1571-5027(07)20001-4).

Viswanathan, M., and Rosa, J. A. 2010. "Understanding subsistence marketplaces: Toward sustainable consumption and commerce for a better world," Journal of Business Research (63:6), Elsevier Inc., pp. 535-537 (doi: 10.1016/j.jbusres.2009.06.001).

Weidner, K. L., Rosa, J. A., and Viswanathan, M. 2010. "Marketing to subsistence consumers: Lessons from practice," Journal of Business Research (63:6), Elsevier Inc., pp. 559-569 (doi: 10.1016/j.jbusres.2009.02.022).

Williamson, O. E. 1985. The economic institutions of capitalism : firms, markets, relational contracting, Free Press (doi: 10.1007/978-3-8349-9320-5_6).

Yin, R. K. 2009. Case Study Research: Design and MethodsApplied Social Research Methods, SAGE Publications.

Zukin, S., and Dimaggio, P. 1990. Structures of Capital: The Social Organization of the EconomyMonographs; V. 109, Cambridge University Press. 


\section{Appendix}

\section{Details on the included cases}

\section{Aravind Eye Care (Case 1)}

\section{http://www.aravind.org/}

Aravind was selected as it is an exemplary and well-established example of a market driving firm from an emerging market (Kumar et al. 2000). It was established in 1972 with an intention of servicing rural communities to cure unnecessary blindness. In India, out of 15 million people who are blind, 12 million are suffering from blindness that is either preventable or curable through a simple cataract operation. However, the lack of access and affordability to quality eye care prohibits the restoring vision. Therefore, Aravind was set up to offer quality eye care at no or low costs to the masses. Over 40 years it has managed to overcome several constraints in the Indian market and establish new inclusive healthcare infrastructure in India (Kumar et al. 2000). The high societal acceptance and rapid replication of their business model in bringing affordable healthcare services to the masses justifies Aravind as an appropriate case example for this study.

\section{Ziqitza Healthcare Limited (Case 2)}

\section{http://zhl.org.in/}

Ziqitsa was founded in 2002 with the mission of providing emergency medical services to all Indian citizens, regardless of their ability to pay. India lacks a robust emergency transport system, around 30 per cent of accident victims die due to delays in transportation or lack of access to timely medical care. The majority of the population relies heavily on auto rickshaws or taxis or personal vehicles for emergency transport owing to their perceived low-cost and easy availability. Services provided to transport patients requiring emergency medical attention are 
either unavailable or unreliable with high response time and no virtual communication with the hospitals. To fill in this gap, Ziqitsa established itself as a high-quality, affordable, efficient and reliable Emergency Medical Care (EMS) service provider. Ziqitsa has expanded its geographic reach at a rapid pace since its inception and was instrumental in changing the face of EMS in India. They have led many state governments to show willingness towards provision of medical helplines and transport services within India.

\section{LifeSpring Hospitals Private Limited (Case 3)}

\section{http://www.lifespring.in/}

LifeSpring is an expanding chain of maternity hospitals that provides high quality healthcare to lower-income women and children in India. Through its market-based approach, LifeSpring fills the void of high quality maternal and child healthcare at affordable rates for India's lowincome population. India has one of the highest maternal mortality rates in the world. Compared to government hospitals, often overburdened and lacking quality services, private clinics are so expensive that they are out of reach for lower-income families. Therefore in 2005, LifeSpring focused on narrow specialization, basic maternity and child care services. It not only helped to bring quality maternity services to the BOP but also had an impact on the surrounding market. It also lowered the overall prices in neighborhood hospitals and helped to improve efficiencies in public hospitals by offering alternative maternity services to patients.

\section{GV Meditech Limited (Case 4)}

\section{www.grmeditech.com}

GV Meditech is a Varanasi based healthcare company (founded in 2002) that runs a chain of secondary hospitals, offering high-quality and affordable medical, diagnostic and pharmaceutical services to patients across Uttar Pradesh (UP). UP is home to the largest number 
of urban poor in a single state and has poor healthcare services. GV Meditech offers basic healthcare services at the village level through telemedicine centers, health camps, microclinics and ambulance services. They are not only building healthcare infrastructure in rural areas (through setting up micro-clinics and running training programs), but are also providing employment opportunities to reduce migration of the younger generation to bigger cities. 
Table 1: An Overview of Market Driving Literature

\begin{tabular}{|c|c|c|c|c|c|c|c|c|c|c|c|c|c|}
\hline Categories & Sub-Categories & $\begin{array}{l}\text { Kumar et al. } \\
2000\end{array}$ & \begin{tabular}{|l} 
Jaworski et \\
al. 2000
\end{tabular} & $\begin{array}{l}\text { Tuominen } \\
\text { et al. } 2004\end{array}$ & $\begin{array}{l}\text { Berghman et al. } \\
2006\end{array}$ & \begin{tabular}{|l|} 
Carrillat et al. \\
2004
\end{tabular} & Ghauri et al. 2016 & Harris \& Cai2002 & \begin{tabular}{|l} 
Narver et al. \\
2004
\end{tabular} & \begin{tabular}{|l|} 
Hills \& \\
Bartkus 2007
\end{tabular} & \begin{tabular}{|l} 
Ghauri et al. \\
2011
\end{tabular} & \begin{tabular}{|l|} 
Tarnovskaya et \\
al. 2008
\end{tabular} & Elg et al. 2008 \\
\hline \multirow[b]{4}{*}{$\begin{array}{c}\text { External } \\
\text { Dimensions }\end{array}$} & $\begin{array}{l}\text { Change } \\
\text { customer } \\
\text { perception }\end{array}$ & $\begin{array}{l}\text { Discontinuous } \\
\text { value } \\
\text { proposition }\end{array}$ & \begin{tabular}{|l|} 
Reshaping \\
market \\
behavior \\
\end{tabular} & $\begin{array}{l}\text { Partnering } \\
\text { with } \\
\text { customer }\end{array}$ & $\begin{array}{l}\text { New value } \\
\text { propositions }\end{array}$ & \begin{tabular}{|l} 
Influencing \\
customer values
\end{tabular} & $\begin{array}{l}\text { New value } \\
\text { propositions }\end{array}$ & \begin{tabular}{|l} 
Revolutionary \\
value \\
proposition
\end{tabular} & \begin{tabular}{|l} 
Innovative \\
value \\
propositions
\end{tabular} & \begin{tabular}{|l} 
Changing \\
customer \\
perceptions
\end{tabular} & \begin{tabular}{|l} 
Changing \\
customer \\
perceptions
\end{tabular} & \begin{tabular}{|l} 
Revolutionary \\
value \\
proposition \\
\end{tabular} & \\
\hline & $\begin{array}{l}\text { Modify } \\
\text { competition }\end{array}$ & $\begin{array}{l}\text { Changing } \\
\text { industry } \\
\text { fundamentals }\end{array}$ & \begin{tabular}{|l|} 
Reshaping \\
market \\
structure \\
\end{tabular} & & & Reshaping market & & $\begin{array}{l}\text { Changing market } \\
\text { composition }\end{array}$ & & & \begin{tabular}{|l|} 
Modifying \\
competitive \\
conditions
\end{tabular} & \begin{tabular}{|l|} 
Changing \\
market \\
composition \\
\end{tabular} & \\
\hline & $\begin{array}{l}\text { Restructure } \\
\text { supply chain }\end{array}$ & $\begin{array}{l}\text { Channel } \\
\text { reconfiguration }\end{array}$ & $\begin{array}{l}\text { Reshaping } \\
\text { value chain }\end{array}$ & & $\begin{array}{l}\begin{array}{l}\text { Redesigning } \\
\text { industry/supply } \\
\text { chain }\end{array} \\
\end{array}$ & & $\begin{array}{l}\text { Networking with } \\
\text { partners/suppliers }\end{array}$ & $\begin{array}{l}\text { Relationship } \\
\text { formation }\end{array}$ & & & $\begin{array}{l}\text { Re-structuring } \\
\text { supply chain }\end{array}$ & \begin{tabular}{|l|} 
Creating strong \\
relationships \\
with suppliers \\
\end{tabular} & \begin{tabular}{|l|} 
Reshaping \\
global supply \\
chain/network \\
\end{tabular} \\
\hline & Societal impact & & & & & & & & & & \begin{tabular}{|l} 
Influencing \\
larger society
\end{tabular} & & $\begin{array}{l}\text { Building local } \\
\text { trust } \\
\text { Engaging in } \\
\text { politics }\end{array}$ \\
\hline \multirow[b]{2}{*}{$\begin{array}{c}\text { Internal } \\
\text { Dimensions }\end{array}$} & \begin{tabular}{|l} 
Business \\
structure/ \\
processes
\end{tabular} & $\begin{array}{l}\text { Unique business } \\
\text { system }\end{array}$ & & & $\begin{array}{l}\text { New business } \\
\text { model }\end{array}$ & & $\begin{array}{l}\text { Unique business } \\
\text { system }\end{array}$ & $\begin{array}{l}\text { Unique business } \\
\text { structure }\end{array}$ & \begin{tabular}{|l} 
Innovative \\
internal \\
processes \\
\end{tabular} & & & \begin{tabular}{|l|} 
Radical \\
business \\
system \\
\end{tabular} & \\
\hline & $\begin{array}{l}\text { Organizational } \\
\text { capabilities }\end{array}$ & & & $\begin{array}{l}\text { Learning/ } \\
\text { responsive } \\
\text { capability }\end{array}$ & $\begin{array}{l}\text { Absorptive } \\
\text { capacity } \\
\text { Organizational } \\
\text { competency- } \\
\text { culture }\end{array}$ & \begin{tabular}{|l} 
Transformational \\
leadership \\
Innovative culture
\end{tabular} & \begin{tabular}{|l} 
Configuration \\
capability \\
Learning capability \\
Branding capability \\
\end{tabular} & $\begin{array}{l}\text { Local Sensitivity } \\
\text { Market } \\
\text { responsiveness }\end{array}$ & & & \begin{tabular}{|l|} 
Learning \\
capability \\
Branding \\
capability \\
Configurational \\
capability \\
Networking \\
capability \\
\end{tabular} & \begin{tabular}{|l} 
Organization \\
culture \\
Learning \\
capability \\
\end{tabular} & \\
\hline \multirow[b]{2}{*}{$\begin{array}{l}\text { Type of } \\
\text { market }\end{array}$} & $\begin{array}{l}\text { Emerging } \\
\text { Markets }\end{array}$ & $\begin{array}{l}\text { Emerging } \\
\text { markets }\end{array}$ & & & & & & \begin{tabular}{|l}
$\begin{array}{l}\text { Emerging } \\
\text { markets }\end{array}$ \\
\end{tabular} & & & & $\begin{array}{l}\text { Emerging } \\
\text { markets }\end{array}$ & $\begin{array}{l}\text { Emerging } \\
\text { markets }\end{array}$ \\
\hline & \begin{tabular}{|l|} 
Developed \\
Markets
\end{tabular} & \begin{tabular}{|l} 
Developed \\
Markets
\end{tabular} & $\begin{array}{l}\text { Developed } \\
\text { Markets }\end{array}$ & $\begin{array}{l}\text { Developed } \\
\text { Markets }\end{array}$ & \begin{tabular}{|l} 
Developed \\
Markets
\end{tabular} & $\begin{array}{l}\text { Developed } \\
\text { Markets }\end{array}$ & Developed Markets & & \begin{tabular}{|l} 
Developed \\
Markets
\end{tabular} & \begin{tabular}{|l} 
Developed \\
Markets
\end{tabular} & & & \\
\hline \multirow{2}{*}{$\begin{array}{c}\text { Type of } \\
\text { Enterprise }\end{array}$} & $\begin{array}{l}\text { Traditional for- } \\
\text { profit }\end{array}$ & For-profit & & For-profit & For-profit & & For-profit & For-profit & For-profit & & & & For-profit \\
\hline & \begin{tabular}{|l} 
Social Enterprise \\
\end{tabular} & Social & & & & & & & & & & & \\
\hline
\end{tabular}


Table 2: Market Driving Social Enterprises across the Hybrid Spectrum

\begin{tabular}{|c|c|c|c|c|c|}
\hline $\begin{array}{l}\text { Case } \\
\text { No. }\end{array}$ & $\begin{array}{l}\text { Social } \\
\text { Enterprise } \\
\text { Type }\end{array}$ & Name & Normative Legitimacy & Regulative Legitimacy & Cognitive Legitimacy \\
\hline 1 & Non-profit & $\begin{array}{l}\text { Aravind } \\
\text { Eyecare }\end{array}$ & $\begin{array}{l}\text { - Regional focus - (only in Tamil Nadu ) } \\
\text { - Developing relationships with locals (Working } \\
\text { with local community workers, paramedics, } \\
\text { opinion leaders, teacher, conducting health and } \\
\text { outreach camps) } \\
\text { - Recruiting locals (LAICO** - educating local } \\
\text { workforce) } \\
\text { - Transparency and quality assurance }\end{array}$ & $\begin{array}{l}\text { - Collaboration with government (state and central) } \\
\text { - Collaboration with insurance companies }\end{array}$ & $\begin{array}{l}\text { - Hub \& spoke model (Hub at } \\
\text { Madurai, } 5 \text { regional hospitals and } \\
18 \text { mission center) } \\
\text { - LAICO catalyzing new } \\
\text { entrepreneurs (supporting over } \\
350 \text { ventures) }\end{array}$ \\
\hline 3 & For-profit & $\begin{array}{l}\text { LifeSpring } \\
\text { Hospitals }\end{array}$ & $\begin{array}{l}\text { - Regional focus (women from poor working } \\
\text { communities in Hyderabad) } \\
\text { - Developing relationships with locals (Outreach } \\
\text { and educational camps targeted towards family } \\
\text { members) } \\
\text { - Recruiting local workforce } \\
\text { - Price transparency (Standardized and protocol- } \\
\text { based maternity care, transparent pricing holding } \\
\text { price for } 2 \text { years }\end{array}$ & $\begin{array}{l}\text { - Collaboration with other stakeholders } \\
\text { (partnerships with diagnostics, pharmacies, blood } \\
\text { banks, hospitals, NGOs*) }\end{array}$ & $\begin{array}{l}\text { - Cluster Approach (Establishing } \\
\text { multiple hospitals in same city) } \\
\text { - Organic growth - Establishing fully } \\
\text { owned subsidiaries within focus } \\
\text { regions }\end{array}$ \\
\hline 4 & For-profit & GV Meditech & $\begin{array}{l}\text { - Regional focus (areas in and around Banaras) } \\
\text { - Developing relationships with locals (working } \\
\text { withNGO workers, opinion leaders, school } \\
\text { teachers, paramedics \& conducting camps) } \\
\text { - Recruiting local workforce (Training local } \\
\text { population with basic paramedic skills) }\end{array}$ & $\begin{array}{l}\text { - Collaboration with government (through social } \\
\text { welfare schemes) } \\
\text { - Collaboration with other stakeholders } \\
\text { (Partnerships with public and private firms, NGOs, } \\
\text { banks, insurance companies) }\end{array}$ & $\begin{array}{l}\text { - Hub \& Spoke model (Establishing } \\
\text { services at } 3 \text { levels- } 6 \text { micro clinics, } \\
2 \text { micro clinic plus, one main hub) } \\
\text { - Organic growth }\end{array}$ \\
\hline
\end{tabular}


Table 3: Conditions for Normative Legitimacy

\begin{tabular}{|l|c|c|c|c|}
\hline Conditions & Case 1 & Case 2 & Case 3 & Case 4 \\
\hline Regional Focus & $\mathrm{X}$ & & $\mathrm{X}$ & $\mathrm{X}$ \\
\hline $\begin{array}{l}\text { Developing Relationships at the } \\
\text { BoP }\end{array}$ & $\mathrm{X}$ & $\mathrm{X}$ & $\mathrm{X}$ & $\mathrm{X}$ \\
\hline $\begin{array}{l}\text { Recruiting a Local BoP } \\
\text { Workforce }\end{array}$ & $\mathrm{X}$ & $\mathrm{X}$ & $\mathrm{X}$ & $\mathrm{X}$ \\
\hline $\begin{array}{l}\text { Standardization of Service } \\
\text { (protocols, quality and price } \\
\text { assurance) }\end{array}$ & & $\mathrm{X}$ & \\
\hline
\end{tabular}

Table 4: Conditions for Regulative Legitimacy

\begin{tabular}{|l|c|c|c|c|}
\hline Conditions & Case 1 & Case 2 & Case 3 & Case 4 \\
\hline $\begin{array}{l}\text { Collaboration with } \\
\text { Government }\end{array}$ & $\mathrm{X}$ & $\mathrm{X}$ & & $\mathrm{X}$ \\
\hline $\begin{array}{l}\text { Collaboration with Non- } \\
\text { Government Stakeholders }\end{array}$ & $\mathrm{X}$ & & $\mathrm{X}$ & $\mathrm{X}$ \\
\hline
\end{tabular}

Table 5: Conditions for Cognitive Legitimacy

\begin{tabular}{|l|c|c|c|c|}
\hline Conditions & Case 1 & Case 2 & Case 3 & Case 4 \\
\hline Hub and Spoke model & $\mathrm{X}$ & & & $\mathrm{X}$ \\
\hline PPP model & & $\mathrm{X}$ & & \\
\hline $\begin{array}{l}\text { Open model of sharing } \\
\text { best practices }\end{array}$ & $\mathrm{X}$ & & & \\
\hline Cluster Approach & & & $\mathrm{X}$ & \\
\hline
\end{tabular}


Figure 1: Hybrid businesses. Adapted from Alter (2007), Boyd et al. (2009) and Bocken et al.

(2016)

Mainly

mission

oriented

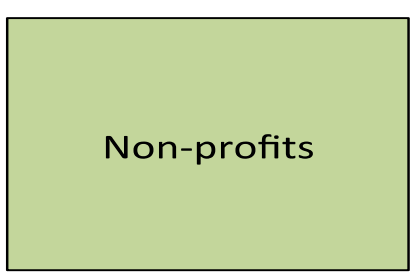

Market and

mission

oriented

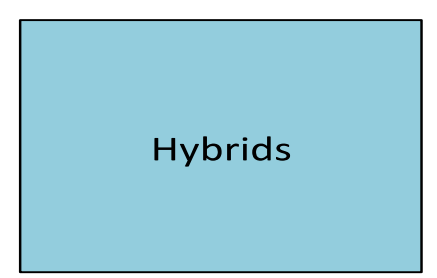

Social enterprise

- Benefits

corporations

- Social businesses

Figure 2: Conceptual Framework of Market Driving Social Enterprises in Emerging Markets.

Adapted from Jaworski et al. 2000 and Ghauri et al. 2011

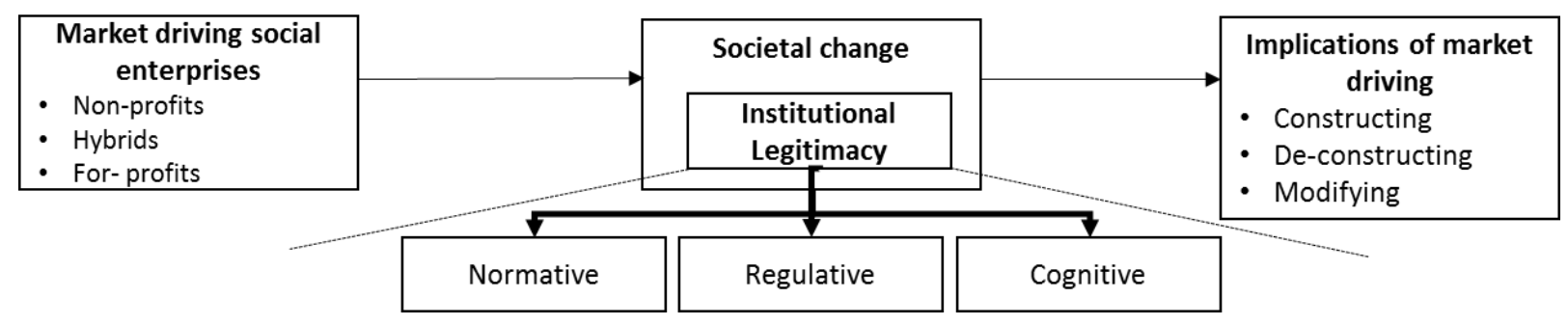


Figure 3: Market Driving Social Enterprises Constructing New Markets at the BoP

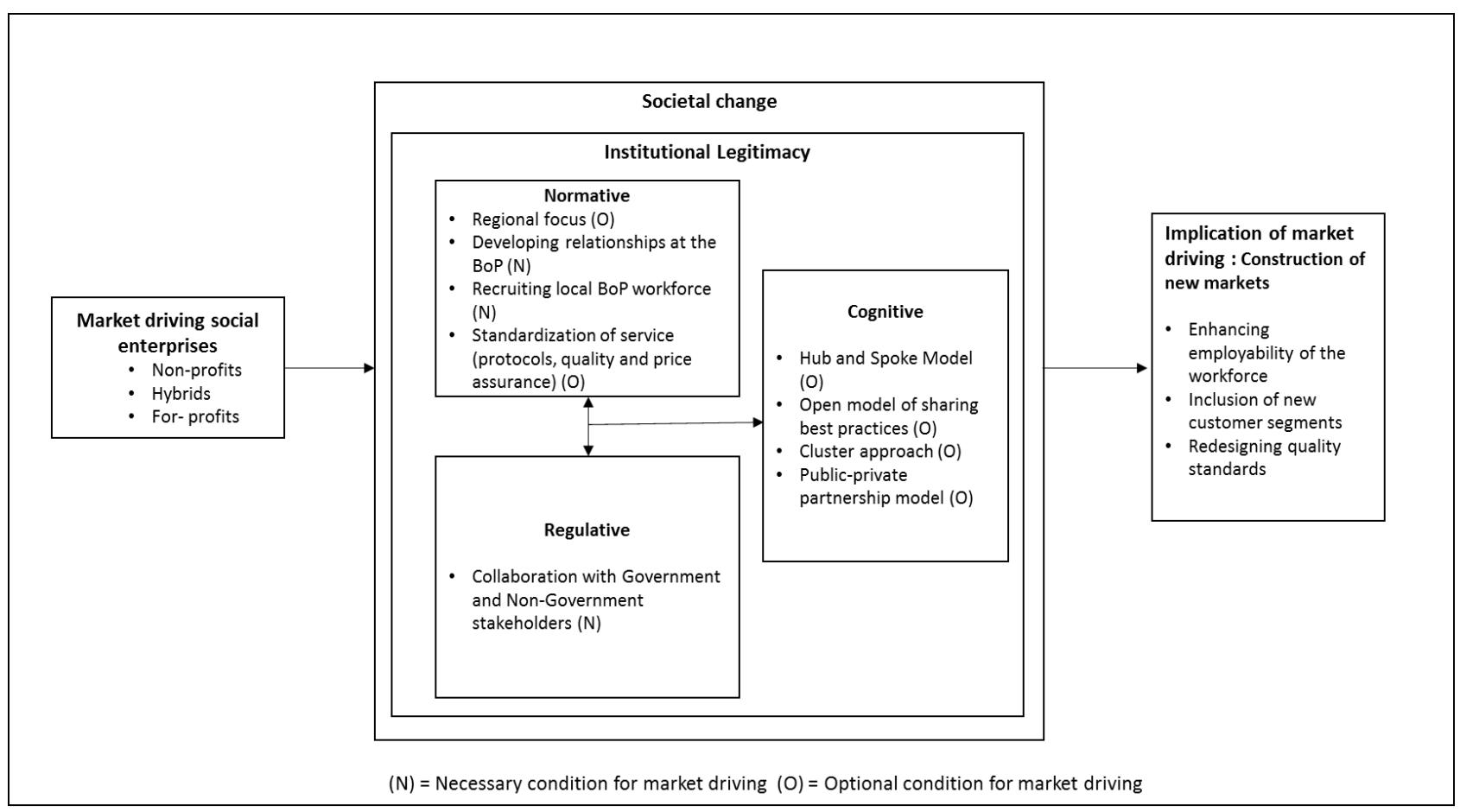

